\title{
A serenidade e a filha do amor: dissonâncias em Love child
}

\author{
Serenity and the daughter of love: dissonances in Love child \\ La serenidad y la hija del amor: disonancias en Love child
}

Arlinda B. Moreno | morenoar@fiocruz.br

Fundação Oswaldo Cruz, Escola Nacional de Saúde Pública Sérgio Arouca, Departamento de Epidemiologia e Métodos Quantitativos em Saúde. Rio de Janeiro, Brasil.

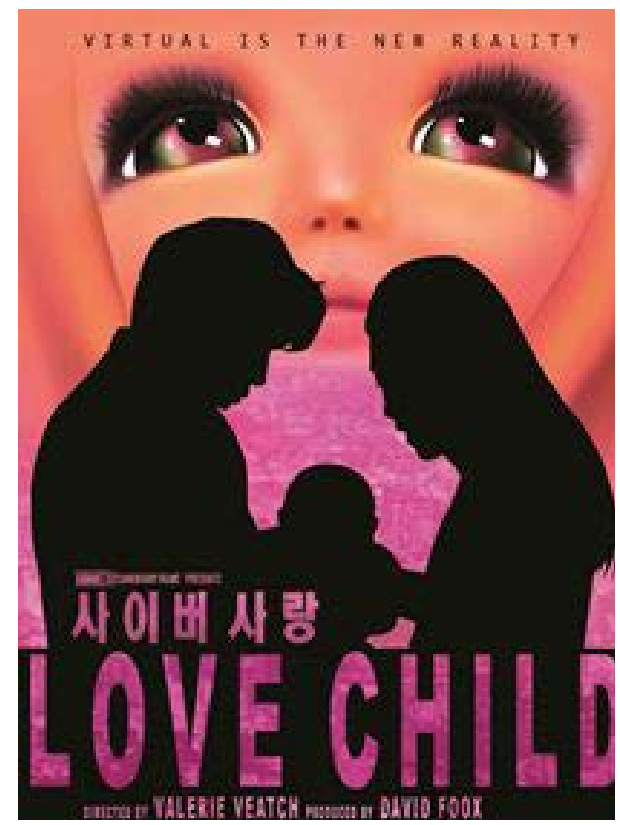

Cartaz do documentário Love Child

\section{Ficha técnica:}

Nome original: Love Child

Diretor: Valerie Veatch

Produtor: David Foox

Diretor de fotografia: Daniel B. Levin

Produtores executivos: John Legere,

Christina Legere, Elizabeth Legere e

Andrew Teng Produtores: Daniel B. Levin,

Danny Kim and Minji Kim.

\section{Ficha técnica HBO:}

Supervisão de produção: Sara Bernstein, Produtor executivo: Sheila Nevins.

Ano: 2014

Países de origem: Coreia do Sul; Estados Unidos Gênero: Documentário

Cor: colorido

Duração: 75 min 


\section{Sinopse}

Nesse documentário sul-coreano, um casal de Hwaseong tenta sobreviver angariando fundos por meio de um jogo na internet. Para tanto, eles frequentam intensamente um cybercafé e, para jogarem por mais tempo de forma mais econômica, compram pacotes de horários. No jogo, têm de vencer várias fases e, para isso, uma personagem avatar, mescla de fada e criança, necessita de cuidados especiais para poder conduzir os jogadores à vitória. Em uma manhã, de volta para casa depois de jogarem por mais de dez horas seguidas, encontram sua filha de três meses morta por desnutrição. O filme acompanha o período de julgamento desse casal por negligência e assassinato de incapaz e revela-se como o primeiro caso de adicção de jogos da internet - perfil psicológico que permite atenuação da pena imputada aos pais de Sarang.

Palavras-chave: saúde mental; psicologia; dependência; internet; jogos de vídeo.

\section{Synopsis}

In this South Korean documentary, a couple from Hwaseong tries to survive by raising funds through an internet game. In order to do so, they attend a cybercafé extensively and, to play for a longer time in a more economical way, they buy time-based rate packages. In the game, a couple has to win several stages and for this an avatar character, a mix of fairy and child, needs special care to be able to lead the players to victory. One morning, back to home after playing for more than ten hours in a row, they find their three-month-old daughter died of malnutrition. The movie follows the trial of this couple charged of negligence and murder of the incapable and it is revealed as the first case of internet games addiction - psychological profile that allows mitigation of the punishment imputed to Sarang's parents.

Keywords: mental health; psychology; dependency; internet; video games.

\section{Sinopsis}

En ese documental de Corea del Sur, una pareja de Hwaseong intenta sobrevivir por medio de recaudación de fondos en un juego de internet. Por eso, frecuentan hasta el agotamiento un cibercafé. Para jugar demasiado a precios bajos, ellos compran paquetes horarios. En el juego, la pareja tiene de superar diversas etapas y un personaje avatar, mezcla de hada y niño, necesita cuidados especiales para conducir a los jugadores hasta la victoria. De vuelta a casa por la mañana, después de jugar durante más de diez horas seguidas, descubren que su hija de tres meses de edad es muerta por desnutrición. La película sigue el período de juicio de esta pareja por el crimen de negligencia y asesinato de incapaz y es el primer caso de la adicción de juegos de internet - perfil psicológico que permite la atenuación de la pena de los padres de Sarang.

Palabras clave: salud mental; psicología; dependencia; internet; videojuegos.

Contribuição dos autores: A autora é responsável por todo o texto.

Declaração de conflito de interesses: a autora declara que não há quaisquer conflitos de interesse.

Fontes de financiamento: não há

Histórico do artigo: Submetido: 12.jan.2017 | Aceito: 13.fev.2017 | Publicado: 31.mar.2017

Licença CC BY-NC atribuição não comercial. Com essa licença é permitido acessar, baixar (download), copiar, imprimir, compartilhar, reutilizar e distribuir os artigos, desde que para uso não comercial e com a citação da fonte, conferindo os devidos créditos de autoria e menção à Reciis. Nesses casos, nenhuma permissão é necessária por parte dos autores ou dos editores. 


\section{A serenidade e a filha do amor: dissonâncias em love child}

No oriente o sol nasce esplendoroso com uma luminosidade que ataca a retina do espectador. Na era tecnológica da próspera Coreia do Sul, um relógio de parede de uma unidade policial não faz tic-tac, mas sim, emite uma batida repetitiva e surda do que seria um contador de tempo digital que, por estar parado, antagonicamente, emula uma frequência cardíaca.

Um oficial de polícia e um homem de meia-idade travam o seguinte diálogo:

- Por que você está aqui?

A resposta é emitida de forma monocórdica:

- Eu estou aqui porque minha filha morreu.

- Quando e onde sua filha morreu?

- Semana passada, na minha casa.

- Ok. Qual é a sua ocupação?

- Eu não tenho trabalho.

- Qual o nome do seu bebê?

- Sarang.

- Você sabe a hora em que seu bebê morreu?

- Penso que em torno de 5hoom da manhã.

- Por que você não sabe exatamente?

- Porque eu cheguei em casa depois disso.

- Onde você foi?

- Eu estava na PC Room.

- Ok. Então você deixou seu bebê de três meses sozinho em casa, jogou por toda noite na PC Room e voltou às 05 hoom da manhã?

- Não, nós voltamos às $07 h o o m$.

- Às o7hoom? Por quanto tempo você jogou no computador?

- Mais de dez horas, eu acho.

- O que você acha que causou a morte do bebê?

- Eu não tenho certeza. Ela era um bebê prematuro.

Assim começa Love child, um documentário produzido pela HBO que acompanha, por 24 meses, o julgamento de um casal sul-coreano acusado de negligência e assassinato de incapaz, em 2010. As investigações policiais realizadas descobriram que, para sobreviver, o casal angariava fundos por meio de 
prática recentemente legalizada na Coreia do Sul e conhecida no mundo virtual como Gold Farming pontos ganhos em jogos virtuais que podem ser negociados e transformados em dinheiro. Alguns jogadores chegam a lucrar grandes quantias de dinheiro com essa troca de pontos.

Para poderem jogar por inúmeras horas seguidas, o casal comprava, porque era mais barato, pacotes de horários em um cybercafé (PC Room) e lá despendiam cerca de seis a 12 horas por dia enquanto, em casa, sua bebê ficava sozinha e faminta. Paradoxalmente, o jogo de fantasia ao qual o casal se dedicava era o Prius online, versão sul-coreana criada em 2008, em um ambiente 3D e classificado como um MMORPG - Massively Multiplayer Online Role-Playing Game, no qual, para vencer etapas, é necessário cuidar de um avatar feminino, mescla de fada e criança, de nome Anima (palavra cuja origem latina denota sopro, ar, brisa, e que, no uso corrente, passou a significar princípio vital, alma) ${ }^{1}$. No jargão dos jogadores online essa categoria de personagem é denominada 'avatar de dinheiro' e, nesse tipo de jogo, os jogadores são convidados a assumirem um personagem (também um avatar) e a se inserirem nos ambientes, cenas e papéis (com apelos emocionais) requeridos por suas regras. A depender do nível do jogo que alcançam, os jogadores podem ganhar bônus que permitem acessar novas etapas.

O filme é montado a partir de cenas captadas do próprio jogo Prius, de reportagens televisivas que abordam o caso da morte de Sarang (nome cujo significado, por azar ou ironia, como bem refere o policial que fez o registro do caso, é amor em coreano) e o crescimento tecnológico da Coreia do Sul, das entrevistas durante a investigação policial, com declarações do principal detetive do caso, Young Jin-Park, e do defensor público que acolheu os réus, Ji-Hoon Lee, além de um dos desenvolvedores do jogo, Tae-geon Kim, do jornalista britânico Andrew Salmon e de pessoas ligadas ao cybercafé PC Room, seja como frequentadores, seja trabalhadores.

Segundo o detetive Young Jin-Park, quando a polícia chegou ao local de falecimento de Sarang, ela estava deitada em um cobertor, coberta até o peito com uma colcha, morta em um porão excessivamente desarrumado. Sua aparência era de extremo baixo peso e a autópsia confirmou que a bebê havia morrido por desnutrição. Ao sair do hospital, após seu nascimento, Sarang pesava 2,9 kg e, quando morreu, aos três meses, estava com dois quilos e meio. Ao lado de seu corpo, uma mamadeira de leite em pó apodrecido e cheia de cabelos. O detetive supunha que o casal alimentava a criança com esse alimento estragado. Sarang foi cremada no verão de 2010 e suas cinzas foram espalhadas entre os restos de outros humanos que já haviam sido cremados.

Na condução do inquérito, por um lado, o detetive Young Jin-Park declarou que estava surpreso com a ausência de emoção no relato dos pais acerca do evento, com a agravante de o casal ter fugido da cidade após sua ordem de prisão ter sido decretada. Por outro, um defensor público acolheu o caso e justificou tê-lo feito porque simpatizou com o infrator. Esse foi o primeiro episódio desse tipo na Coreia do Sul e o casal esperava que, com o passar do tempo, o incidente fosse esquecido e que eles pudessem levar uma vida calma.

O filme destaca o fato de que o casal não teve sua relação aprovada pelos familiares, uma vez que a diferença de idade entre ambos era bastante grande, sendo o homem bem mais velho do que a mulher (41 e 25 anos, respectivamente ${ }^{2}$ ), que os mesmos não tinham trabalho fixo e diziam ganhar dinheiro com os jogos por computador, mesmo vivendo em um país em ascensão meteórica como a Coreia do Sul.

Aliás, uma frase off-screen que parece advir de uma reportagem sobre o desenvolvimento do país anuncia: 'Coreia do Sul, capital digital do mundo'. Os jogos de computador são considerados um esporte nacional na Coreia do Sul e são extremamente afinados com o modo de ser do sul-coreano que, segundo o declarado no filme, tem por tradição uma vida comunitária. De certa forma, jogar online em rede com um sem-número de outros jogadores mimetiza uma vida em comunidade que apetece aos sul-coreanos.

Em relação ao desenvolvimento do país, em 2009, a Coreia do Sul exportou cerca de 4,2 bilhões de dólares em conteúdos culturais e 50\% deste montante advieram da indústria de jogos por computador. Naquela época, enquanto as transações mundiais com TI - tecnologia da informação - tiveram uma queda de 4,6\%, a indústria sul-coreana de TI cresceu 5,3\%. Além disso, a economia da internet movimentou cerca de US\$ 7,9 bilhões, algo em torno de 7\% do produto interno bruto sul-coreano. 
Segundo matéria produzida pela jornalista Cláudia Trevisan³, no mesmo ano do incidente com Sarang, tendo por base uma economia impulsionada pela alta tecnologia, o PIB per capita da Coreia do Sul era cerca de três vezes maior do que o brasileiro e o país investia pesadamente na melhoria do nível educacional de sua população. Vale lembrar que tudo isso se deu após a nação ter superado uma guerra, entre os anos 1950 e 1953, que dizimou cerca de $5 \%$ da população civil e destruiu cerca de um quarto da riqueza da nação, transformando o país em um dos mais pobres do mundo.

Já no início dos anos 2000, uma pesquisa realizada com 1.440 jovens sul-coreanos, pela Comissão de Proteção à Juventude, revelou que 60\% deles se declaravam viciados em jogos da internet. Além disso, cerca de 70\% da população de quase 48 milhões de habitantes (na época) tinham acesso à internet e cerca de $23 \%$ o faziam em conexões de alta velocidade 4 .

Em 2010, mesmo ano da morte de Sarang, a Coreia do Sul contava com uma população de cerca de 50 milhões de habitantes e um IDH - Índice de Desenvolvimento Humano considerado muito elevado $(0,898)$, ocupando o $17^{\circ}$ lugar no mundo .

$\mathrm{O}$ argumento de que a adicção de jogos online era uma incapacidade física e mental dos pais de Sarang, depois de os mesmos terem sido avaliados por especialistas em saúde mental, foi utilizado pelo defensor público para realizar sua defesa, uma vez que a lei sul-coreana prevê diminuição de penas para incapacitados. Mesmo sendo um assunto controverso, nesse caso, considerou-se que a capacidade de discernimento daqueles afetados por essa nova manifestação psíquica (a adicção de jogos online) estava tão (ou mais) afetada do que a de adictos de álcool e outras drogas ilícitas ou de jogos de apostas. A tese central era a de que o casal não conseguia mais distinguir o mundo real do mundo virtual. Afinal, Anima poderia ser ressuscitada caso, no jogo, se alcançasse pontuação suficiente para tanto mas, Sarang não era ressuscitável.

No final do julgamento, no momento da sentença, a mãe de Sarang estava grávida. O casal prometeu que nunca mais jogaria pela internet e que o fato não se repetiria com a segunda criança. Julgados por assassinato involuntário, Kim, o pai, recebeu uma pena de 12 meses e a mãe não foi condenada.

Depois desse primeiro caso, várias clínicas para recuperação de adiç̧ão de jogos online foram abertas na Coreia do Sul. O filme apresenta um processo de dessensibilização progressiva (técnica característica da psicologia cognitivo-comportamental) no qual, curiosamente, são apresentadas em uma tela de computador cenas relaxantes, um video game e, na sequência, cenas que causam aversão. A chamada "Lei do Desligamento" foi sancionada pelo Ministério da Cultura da Coreia do Sul proibindo menores de 16 anos de jogarem em cybercafés entre meia-noite e seis horas da manhã.

Depois de anos ganhando popularidade, o servidor do Prius Online's Korean foi desligado permanentemente em 17 de dezembro de 2013. Mas, uma miríade de outros jogos foi lançada e a expansão do mercado conta com a possibilidade de utilização de equipamentos mais modernos como os smartphones e tablets. Estimou-se, na época do documentário, que cerca de dois milhões de sulcoreanos sofriam de adicção de jogos da internet.

Mas, o que tudo isso tem a ver com a Serenidade como sugere o título desta resenha?

Pode parecer tão estranha essa associação quanto é bizarro o caso relatado no documentário. Para orientar essa argumentação, será necessário invocar Heidegger ${ }^{6}$ e sua declaração: "A ausência-de-pensamentos é um hóspede sinistro que, no mundo atual, entra e sai em toda a parte".

Sim, essa intermitência do pensamento, essa multiface dos tipos de pensar que Heidegger ${ }^{6}$ explana em seu texto "Serenidade" acompanhou toda a visada que tive em relação a esse filme.

Nesse pequeno texto publicado em 1955, um discurso em homenagem ao compositor alemão, Conradin Kreutzer, o filósofo chama a atenção para dois tipos de pensamento legítimos e necessários: o pensamento que calcula e a reflexão que medita. O primeiro, vaga de oportunidade em oportunidade e jamais medita porque imerso em seu moto-contínuo calculante. O segundo, necessita da proximidade do que está próximo, uma aderência ao aqui e agora, "na presente hora universal".6. Não existe hierarquia entre esses tipos de pensamento, 
tampouco um é menos espontâneo do que o outro. Mas, ampliar a abrangência do primeiro em detrimento do segundo transforma o humano, inserindo-o profundamente na técnica e apartando-o do que lhe é primordial.

No pensamento calculante o mundo é um objeto, um mundo da técnica. O humano do pensamento calculante não é mundo em sua mundanidade. O humano do pensamento calculante se rendeu à técnica que passa a determinar sua relação com o existente, dominando o planeta ${ }^{6}$.

Heidegger ${ }^{6}$, de certa forma, vaticinou que "as forças dos equipamentos técnicos e dos autômatos apertarão cada vez mais o cerco" e que o humano não estaria preparado para essa vertiginosa transformação do mundo. O "hóspede sinistro" - esse pensamento calculante - dominou o casal protagonista do filme em questão.

Kim e sua mulher não estavam preparados para essa transformação do mundo. A suposta confusão, ausência de limites, entre o mundo virtual e o mundo real, não é nada além da pujança do pensamento calculante sobre o pensamento meditativo. Para Heidegger ${ }^{6}$, o humano carece de lidar adequadamente por meio do pensamento que medita com a avalanche tecnológica que seduz o humano ao pensamento calculante e que invade o cotidiano de maneira avassaladora.

Se o casal tivesse equilibrado pensamento calculante e pensamento meditativo teria se colocado próximo do que está próximo, perto do que se é no mundo e do que se dá no seu instante, no seu acontecimento - ele estaria em-mundo e junto-a Sarang. Mas, “... sem nos darmos conta, estamos de tal modo apegados aos objetos técnicos que nos tornamos seus escravos”. É magnífica a forma como essa frase heideggeriana escrita há mais de sessenta anos se mostra atual.

Para Heidegger ${ }^{6}$, a serenidade para com as coisas (die Gelassenheit zu den Dingen) é uma atitude do humano que deve acomodar simultaneamente o sim e o não em relação ao mundo técnico, deixar que os objetos técnicos estejam dentro e fora de nosso cotidiano, tratando as coisas (os objetos e a técnica) como algo que não é absoluto (reificado), mas sim, dependentes de algo superior. A serenidade irmana-se à abertura ao mistério (die Offenheit für das Geheimnis) e é por essa fenda que o humano pode se manter aberto ao sentido oculto no mundo técnico.

O que dizer então da dissonância mencionada no título desta resenha? A dissonância que se apresenta no documentário é, pois, o descompasso entre o pensamento calculante e o pensamento meditativo no casal que protagoniza o filme.

Uma frase dita por Kim, pai de Sarang, sumariza a biografia de sua filha: "Eu espero que ela seja feliz para sempre no paraíso e eu me sinto triste como pai”. Seria, então esse paraíso algo da ordem do real ou do virtual? Seria essa frase filha do pensamento calculante? Seria ele (o pensamento calculante) o único a reger a estrada desse casal?

Em seu texto, Heidegger ${ }^{6}$ teme que o pensamento calculante venha a ser o "único pensamento admitido e exercido" pelo humano. Se, por ventura, esse foi o caso exposto em "Love child" (e eu penso que sim), o casal, nas palavras do filósofo se deixou "prender, enfeitiçar, ofuscar e deslumbrar" pela revolução da técnica, rejeitando e renegando o que o humano tem de mais próprio - "o fato de ser um ser que reflete".

Para a Filha o amor (título do filme em português) não foi possível um encontro com a Serenidade. Sarang encontrou um casal enfeitiçado por um jogo de fantasia. Anima, o avatar, morria e ressuscitava. Sarang, a criança, era um ser-para-a-morte - humana como qualquer um de nós lançados ao mundo. Anima era parte do mundo das coisas e, talvez por ser fada, e, por isso mesmo, conter, no mimetismo dos avatares, o pensamento calculante do casal protagonista, rompeu a barreira do mundo das coisas e se tornou o feitiço da técnica. Sarang por estar ali mesmo, ser o aqui e o agora do casal, clamava para que pai e mãe se demorassem junto-a (e com) ela para que o pensamento que medita cuidasse do ser que é finito. Isso não aconteceu. Aconteceu o espalhar das cinzas de Sarang entre as cinzas de outros talvez filhos do pensamento calculante, talvez filhos do pensamento que medita.

Resta, por fim, apenas a esperança de que o pensamento que medita tenha ganhado força e esteja em pé de igualdade no casal que, agora, deve estar cuidando do fruto de uma segunda gravidez. 


\section{Referências}

1. Anima [Internet]. In: Origem da Palavra: site de Etimologia. [local desconhecido]. [citado em 2017 jan.10]. Disponível em: http://origemdapalavra.com.br/site/palavras/anima/.

2. Casal deixa bebê morrer de fome enquanto cria filha virtual na Internet [Internet]. BBC 2010 mar. [citado em 10 jan. 2017]. Disponível em: http://www.bbc.com/portuguese /noticias/ 2010/03/100305 coreiacasal ba.shtml.

3. Trevisan C. O modelo coreano [Internet]. O Estadão. 2010 fev. [citado em 2017 jan.10]. Disponível em: http://internacional.estadao.com.br/blogs/claudia-trevisan/o-modelo-coreano/.

4. Jogadores patológicos: vício em jogos on line vira problema social na Coreia do Sul [Internet]. BNL DATA. 2004 fev. [citado em 2017 jan. 10]. Disponível em: http://www.bnldata.com.br/noticia. aspx?tipo $=2 \& \operatorname{cod}=929$.

5. Coreia do Sul [Internet]. In: Wikipedia. [local desconhecido]. [citado em 2017 jan. 10]. Disponível em: https://pt.wikipedia.org/wiki/Coreia do Sul.

6. Heidegger M. Serenidade. Andrade MM, Santos O, tradutores. Lisboa: Instituto Piaget; 2000.

7. Love child: synopsis [Internet]. In: HBO Documentaries. New York; 2014. [citado em 2017 jan. 09]. Disponível em: http://www.hbo.com/documentaries/love-child/synopsis.html. 